\title{
Large-eddy simulation of subsurface phytoplankton dynamics: an optimum condition for chlorophyll patchiness induced by Langmuir circulations
}

\author{
Ashley Brereton ${ }^{1, *}$, Joseph Siddons ${ }^{2}$, David M. Lewis ${ }^{2}$ \\ ${ }^{1}$ National Oceanography Centre, Joseph Proudman Building, 6 Brownlow Street, Liverpool L3 5DA, UK \\ ${ }^{2}$ Department of Mathematics, University of Liverpool, Liverpool L69 7ZL, UK
}

\begin{abstract}
Phytoplankton patchiness occurs on a plethora of spatial and temporal scales, and can be extremely patchy in both horizontal and vertical directions. This patchiness directly affects the dynamics of the overall bloom; therefore, understanding the mechanisms behind the occurrence of patchiness on each scale is integral to the understanding of plankton bloom dynamics as a whole. This modelling study introduces a mechanism for patch formations, which has received little attention, but is ubiquitous to the oceanic mixed-layer, Langmuir circulations and their interaction with nutrient upwellings to induce patchiness in the plankton. By combining a large-eddy simulation, which resolves Langmuir circulations, with a nutrient-phytoplankton-zooplankton biological model, one can examine the horizontal and vertical patchiness that results from a flux of nutrients into the bottom of the mixed layer. Here, phytoplankton form significant horizontal patchiness at a depth interval where vertical currents from Langmuir cells are apparent and turbulent mixing is not; this comprises the lower region of the surface mixed layer. Aggregations have frequently been observed in lower regions of the surface mixed layer and have been attributed to the high nutrient flux associated with the pycnocline. This modelling study also shows patches occurring in this region and it is hypothesised that Langmuir cells are a catalyst for patchiness. The results clearly demonstrate that for certain levels of wind forcing, which are strong enough to introduce turbulent mixing only to the upper part of the mixed layer whilst inducing deeper Langmuir circulation, patchiness is greatly enhanced.
\end{abstract}

KEY WORDS: Plankton patchiness - Oceanic mixed layer turbulence $\cdot$ Langmuir turbulence · Vertical mixing $\cdot$ Wind forcing $\cdot \mathrm{NPZ}$ model $\cdot$ Nutrient upwelling

\section{INTRODUCTION}

Wide-ranging observations of plankton patchiness have been compiled over the last few decades (Gran \& Braarud 1935, Hulburt 1968, Gohin et al. 2003, Dore et al. 2008). These formations have been detected on a wide range of spatial and temporal scales (Siegel et al. 2002, Martin 2003, Gallager et al. 2004, Beman et al. 2005, Ryan et al. 2006, Mitchell et al. 2008). Phytoplankton aggregations are known to enhance growth rates (Mackas et al. 1985); therefore, understanding the mechanisms behind patch forma-

${ }^{*}$ Corresponding author: ashbre@noc.ac.uk tions can improve modelling forecasts of chlorophyll concentrations. A common behavioural trait of phytoplankton is that they aggregate over a relatively small depth interval of the surface mixed layer (e.g. Macías et al. 2013). This usually occurs below the mixing layer, a wind-driven surface layer of the water column that experiences high turbulent mixing, but above the pycnocline, a deeper layer of the water column that experiences a large change in density over a small depth interval. This layer is generally laminar in nature. Many possible contributing factors have been postulated to explain these depth-dependent

() The authors 2018. Open Access under Creative Commons by Attribution Licence. Use, distribution and reproduction are unrestricted. Authors and original publication must be credited. 
patch formations, including optimum nutrient and light levels, gyrotaxis and diel vertical migration (Durham \& Stocker 2012). It is this depth-dependent behaviour that is the main focus of this paper.

One of the main drawbacks of observational data is that full 3-dimensional (3D) mappings are infeasible to obtain (mean depth profiles or surface satellite data are mainly produced). This means that the biological profile is incomplete-a gap that can be filled by the use of carefully prescribed mathematical models. Many modelling techniques have been employed to study the dynamics of phytoplankton blooms. Large-scale bloom formation and planktonic patchiness has been investigated using large-scale fluid models (Allen et al. 1999, Martin et al. 2002, Oschlies 2002, Koné et al. 2009). However, the drawback of using these models is that the small-scale phenomena are parameterised via a turbulent diffusion hypothesis and a hydrostatic assumption is commonly made. Though this is essential for permitting feasible spatial and temporal resolution for an ocean domain, it is limited by the current knowledge of the nonlinear smallscale processes. On the other side of the spectrum, the gold standard of computational fluid dynamics known as direct numerical simulation has been used to explore the intricate dynamics of phytoplankton in turbulent flows (Durham et al. 2013, Zhan et al. 2014). Though this method is preferable, the domain size is limited (metres) due to the resolution scales needed, so it is not practical for largescale applications. This naturally opens the field to a branch of modelling that captures the full 3D non-hydrostatic physics not captured in primitive equation-type models, while also permitting feasible resolution scales for ocean physics. This branch of modelling is known as large-eddy simulation (LES). Langmuir circulations have received little attention with regard to biological patchiness, although surface aggregates due to Langmuir circulations were first observed as far back as Charles Darwin's HMS Beagle cruise in 1839 (Leibovich 1983). Langmuir circulations control the mixinglayer depth. In addition, the upwelling motions established by the onset of Langmuir turbulence pull nutrient-rich waters up from the bottom of the mixed layer (Craik \& Leibovich 1976, McWilliams et al. 1997, Thorpe 2000, Polton \& Belcher 2007). This promotes biological growth and has the potential to generate significant planktonic patchiness in regions of the water column where the local mixing is insufficient to disperse them. Hence, Langmuir circulations can act as an important physical stimu- lus to enhance biological activity. However, the mechanism of this stimulus has not been studied in any detail and consequently it is poorly understood. This study addresses the interaction between Langmuir circulation and planktonic patchiness by using LES, as this is the only type of model suitable for resolving this particular phenomenon.

The biological model used in this work is a generic type nutrient-phytoplankton-zooplankton (NPZ) model (Baird \& Emsley 1999, Lewis 2005). Conceptually, the NPZ model is slightly different from other 3-state NPZ models in the literature, e.g. Franks et al. (1986), Fasham et al. (1990), and Edwards \& Brindley (1996), in that a mechanistic approach has been adopted in the derivation in some of the terms (see 'Model description'). An important addition for this work is the inclusion of a non-uniform flux of nutrients into the bottom of the surface mixed layer. The LES is then coupled to the NPZ model to facilitate an investigation into the level of vertical and horizontal patchiness induced by the interaction between Langmuir circulations and the nutrient flux. This method of coupling an LES model to a biological model is a relatively new technique and a novel approach to the problem. Only a handful of authors have previously adopted this methodology to investigate the biophysical dynamics (Lewis 2005, Noh et al. 2006, Taylor \& Ferrari 2011). The work in this study builds on the work of Lewis (2005) which, in contrast to this work, was not able to simulate biological timescales (weeks) due to computational restrictions and did not include a non-uniform nutrient flux into the bottom of the mixed layer.

To summarise, this study seeks to show that Langmuir circulations are an important driver for the formation of depth-dependent biological patchiness. We will quantify both the horizontal and vertical phytoplankton patchiness that results from an interaction between a flux of nutrients into the bottom of the mixed layer and the presence of Langmuir circulations.

\section{MODEL DESCRIPTION}

The mathematical framework used to study the biophysical dynamics of the ocean boundary layer centres around the LES-NPZ model constructed by Lewis (2005). The workings of the model will be briefly outlined here. The governing equations for the flow field used in this work comprise a version of the Navier-Stokes equations incorporating surface wave parameterisations, known as the Craik- 
Liebovich equations (Craik \& Leibovich 1976). They are expressed as follows:

$$
\frac{D \boldsymbol{u}}{D t}+f \hat{\boldsymbol{k}} \times\left(\boldsymbol{u}+\boldsymbol{U}_{\mathbf{S}}\right)=-\frac{\nabla \mathrm{p}}{\rho_{0}}+\nabla \cdot v_{\mathrm{T}} \nabla \boldsymbol{u}+\boldsymbol{U}_{\mathbf{S}} \times \boldsymbol{\omega}
$$

Here $\frac{D}{D t}=\frac{\partial}{\partial t}+\boldsymbol{u} \cdot \nabla$, where $\boldsymbol{u}=(u, v, w)$ is the velocity field, $f$ is the Coriolis frequency, $\boldsymbol{U}_{\mathrm{S}}$ the Stokes drift velocity, $\boldsymbol{\omega}=\nabla \times \boldsymbol{u}$ is the vorticity, $p=p_{0}+\rho_{0}\left[2 \boldsymbol{u} \cdot \boldsymbol{U}_{\mathbf{S}}+\left|\boldsymbol{U}_{\mathbf{S}}\right|^{2}\right] / 2$ is a generalized pressure term, $\rho_{0}$ is a reference density of sea water and $v_{\mathrm{T}}$ is the eddy viscosity. Density and temperature are assumed to be constant in this model. The Stokes drift velocity is attributed to the presence of surface waves, which (without loss of generality) are directed along the $x$ axis. In which case $U_{\mathrm{S}}=\left(U_{\mathrm{S}} e^{2 k z}, 0,0\right)$, where $U_{s}=\sigma k a^{2}$, a being the wave amplitude, $k$ the wave number and $\sigma=\sqrt{g k}$ the wave frequency (Phillips 1977). $\boldsymbol{u}$ and $p$ are filtered in space and time, resulting directly from the spatial-temporal discretisation employed. Scales below the discretisation are modelled via the Smagorinsky scheme (Smagorinsky 1963), which is an explicit eddy viscosity model.

Once the flow field has been calculated at a point in time, the results are then fed into the biological model, this is formulated as follows:

$$
\begin{aligned}
\frac{\partial N}{\partial t}+\left(\boldsymbol{u}+\boldsymbol{U}_{s}\right) \cdot \nabla N= & D_{\mathrm{T}} \nabla^{2} N-N \text { uptake by } P \\
& +N \text { recycled from } P \\
\frac{\partial P}{\partial t}+\left(\boldsymbol{u}+\boldsymbol{U}_{\boldsymbol{s}}\right) \cdot \nabla P= & D_{\mathrm{T}} \nabla^{2} P-P \text { growth from } N \\
& +P \text { grazing loss } \\
\frac{\partial Z}{\partial t}+\left(\boldsymbol{u}+\boldsymbol{U}_{\boldsymbol{s}}\right) \cdot \nabla Z= & D_{\mathrm{T}} \nabla^{2} Z-Z \text { growth from } P \\
& -Z \text { mortality }
\end{aligned}
$$

Here, $D_{\mathrm{T}}$ is the turbulent diffusivity of the respective scalar fields calculated by $D_{\mathrm{T}}=v_{\mathrm{T}} / S C$, where $S C$ is a Schmidt number based on the resolution; for this set-up, $S C \sim 0.5$. The 3 non-dimensional scalar fields denoted by $N(x, t)=N^{*} / N_{0}, P(x, t)=P^{*} / P_{0}$ and $Z(x, t)=$ $Z^{*} / Z_{0}$ are representative of nutrients (specifically nitrate), phytoplankton and zooplankton, respectively (where $N_{0}$ in $\mathrm{kg} \mathrm{m}^{-3}$ and $P_{0}$ and $Z_{0}$ in cells $\mathrm{m}^{-3}$ are suitable reference scales). The coupling between the LES flow field, calculated from Eq. (1), and the scalar quantities is represented by the second term in the equations. It assumed that the scalar fields are neutrally buoyant and are all treated as passive tracers, though it is acknowledged that buoyancy and swimming, for example, are tractable mechanisms for aggregation. The derivation of the functional forms of the source-sink terms can be quite involved, so for simplicity it was chosen to only state the functional forms in this study with only a brief description. First, the uptake term is given by:

$N$ uptake by $P=4 \pi r_{p} S h(\varepsilon, z) D_{N} N\left[1-\frac{R_{N_{0}}(z)}{R_{N}^{\max }} N\right] P^{*}$

where $r_{p}$ is the radius of a (spherical) phytoplankton cell and $S h$ is the turbulent Sherwood number, which is dependent on the energy dissipation rate $\varepsilon$. The latter is calculated directly from a preliminary LES simulation of the relevant boundary layer once statistical stationarity has been reached. The ratio $R_{N_{0}}(z) / R_{N}^{\max }$ represents the nitrate storage capacity of the cell to its maximum potential storage capacity. For the biological parameters employed here, this ratio is $\sim 0.5$ and hence whenever $>2$, nutrient uptake falls to zero. Since $r_{p}$ is usually less than the associated Kolmogorov microscale, $\varepsilon$ plays a diminished role in the uptake term. The next 2 terms consist of:

$N$ recycled from $P=$

$\left(1-\beta_{E}\right) \frac{s_{N} P^{*}}{N_{0}} \mu_{P}^{\max } e^{\alpha z} \min \left[1, \frac{R_{N_{0}}(z)}{R_{N}^{\max }} N\right]$

$P$ growth from $N=\beta_{E} \mu_{P}^{\max } e^{\alpha z} \min \left[1, \frac{R_{N_{0}}(z)}{R_{N}^{\max }} N\right] P$

Here $\beta_{E} \in(0.1)$ represents the growth efficiency of the phytoplankton species, $s_{N}$ is the stoichiometry coefficient, $\alpha$ is the light attenuation coefficient of water and $\mu_{P}^{\max }$ represents the maximum growth rate achievable by the phytoplankton species. The next 2 predation terms are given by:

$$
P \text { grazing loss }=J\left(R, T_{\mathrm{R}}, \varepsilon, \sigma_{Z}\right) Z^{*} P
$$

$Z$ growth from $P=\min \left[\mu_{Z}^{\max }, J\left(R, T_{R}, \varepsilon, \sigma_{Z}\right) Y P^{*}\right] Z$

Here $J\left(R, T_{R}, \varepsilon, \sigma_{Z}\right)$ represents the predation rate of a single predator with a spherical perception field of $R$. $T_{\mathrm{R}}$ is the reaction time of the zooplankton species and $\sigma_{Z}$ is the swimming speed of the species. $Y$ is the amount of new zooplankton cells created per phytoplankton cell captured and $\mu_{Z}^{\max }$ is the maximum growth rate (for detailed discussion of the functional form of $J$, see Lewis \& Pedley 2001). $\varepsilon$ has a much larger effect on the predation rate than it does on the phytoplankton uptake rate since $R \sim(1-40) \mathrm{mm}$ is substantially larger than the Kolmogorov microscale. Turbulence increases the number of predator-prey contacts, usually leading to an enhancement of the predation rate. Finally, the equations are closed by the mortality term given by: 


$$
Z \text { mortality }=\mu_{Z}^{\text {death }} Z
$$

Here $\mu_{Z}^{\text {death }}$ is a constant death rate of the zooplankton species.

For an extensive analysis of the NPZ model, including stability analysis, $\varepsilon$-dependent parameters and comparison with the full LES-NPZ model, and for a full list of parameter values used, alongside analysis of the physical LES model directly relevant to the simulations performed in this work see Lewis et al. (2017).

For this study, a series of turbulent boundary layers were generated, each characterised by the values of the Stokes drift velocity $U_{\mathrm{S}}$, and the friction velocity $U$ *. The latter determines the wind-stress boundary condition applied at the surface:

$$
\left.v_{\mathrm{T}} \frac{\partial u}{\partial z}\right|_{z=0}=\frac{\tau}{\rho_{0}}=U^{2}
$$

Here $\tau$ is the surface wind stress. Values of $U$ * were varied between $1.5 \times 10^{-3}$ and $5.0 \times 10^{-3} \mathrm{~m} \mathrm{~s}^{-1}$, roughly equivalent to wind speeds of $U_{10}=1.2-4.0 \mathrm{~m}$ $\mathrm{s}^{-1}$ at $10 \mathrm{~m}$ above the sea surface. The corresponding values of $U_{\mathrm{S}}$ were based on a constant Langmuir number $L a=\sqrt{U_{*} / U_{\mathrm{S}}}=0.3$, a value that corresponds to a fully developed sea (McWilliams et al. 1997, Harcourt \& D'Asaro 2008, Sullivan et al. 2012). Typically, the various boundary layers were spun up from rest for a period $\tau_{\text {spin }} \sim 17 \mathrm{~h}$, until a quasi-equilibrium state was reached before any biological fields were added. Velocity and pressure fields were computed from Eq. (1) over a computational domain of $120 \mathrm{~m} \times 120 \mathrm{~m}$ horizontally and to a mixed (distinct from the mixing) layer depth of $z_{\mathrm{ml}}=33 \mathrm{~m}$, utilising a basic grid of $40 \times$ $40 \times 75$. This implies a regular resolution scale of $\Delta_{X}=$ $\Delta_{y}=3 \mathrm{~m}$ and $\Delta_{z}=0.45 \mathrm{~m}$ (although the vertical resolution was stretched to give greater resolution near the sea surface to resolve the log layer sufficiently). Horizontal periodicity is enforced at the lateral boundaries. At the surface, $w=0$ and zero stress is imposed on $V$. A no-slip condition is imposed at $z=$ $Z_{\mathrm{ml}}$. Lateral periodic boundary conditions are imposed for all scalar quantities. Furthermore, zero flux boundary conditions are imposed for all scalar quantities at the surface and for $P$ and $Z$ at the bottom boundary. For the nutrient field, Williams \& Follows (1998) suggest a positive uniform nutrient background flux should be of the order $2 \times 10^{-8} \mathrm{~mol} \mathrm{~N} \mathrm{~m}^{-2}$ $\mathrm{s}^{-1}$, which is roughly equivalent to $\left\langle w N^{*}\right\rangle=2.8 \times$ $10^{-10} \mathrm{~kg} \mathrm{~m}^{-2} \mathrm{~s}^{-1}$, which helps replenish nutrient losses due to phytoplankton growth. However, this paper is concerned with the possible formation of $P Z$ patchiness in the mixed layer, starting from initially uniform distributions, which can only occur in response to some form of stimulus. The most likely stimulus that could initiate such a response would be a localised surge of nutrients into the mixed layer. This would influence the growth rates of a wide crosssection of phytoplankton species, which, after some lag time, would in turn produce a response higher up the planktonic food chain. Such a nutrient surge might be the result of a heavy river run off, or via a sustained upwelling gyre forcing nutrient-rich deep water into the mixed layer. Vertical fluxes of nutrients also occur naturally when momentum shear associated with internal tides facilitates turbulent mixing and the conversion of barotropic tidal energy to baroclinic dissipation at the pycnocline (Sandstrom \& Elliott 1984, Sharples et al. 2007). Rines et al. (2010) reported observations in Monterey Bay, California, in which patchy horizontal phytoplankton distributions were correlated with the frequency of large-scale, nutrient-rich advection events. Furthermore, patchy distributions of phytoplankton have been observed and correlated to high-frequency internal waves (Lennert-Cody \& Franks 1999). However, for this study, the exact mechanism of the nutrient surge is not particularly important. One is much more interested in its potential effects. To mimic an upwelling event, a localised non-uniform flux of nutrients through the base of the mixed layer was introduced throughout the duration of a simulation. A pocket of turbulence generated via internal wave mixing will advect nutrient-rich water upwards. It will then have to travel through a laminar band of water between the pycnocline and the mixing layer, making the dynamics of the nutrient upwelling diffusive. Therefore, a diffusive flux is imposed near the bottom of the mixed layer. Mathematically, this boundary condition takes the form:

$$
\frac{1}{2.8 \times 10^{-10}} \times\left. D_{\mathrm{T}} \frac{\partial N}{\partial z}\right|_{z=z_{m l+}}=1+Q \exp \left[\frac{-\left(x^{2}+y^{2}\right)}{2 \sigma_{x y}^{2}}\right]
$$

Here $(x, y)$ represents the horizontal coordinates with $-60 \mathrm{~m} \leq x \leq 60 \mathrm{~m}$ and $-60 \mathrm{~m} \leq y \leq 60 \mathrm{~m}, Q$ is the strength of the nutrient flux at the centre and $\sigma_{x y}$ a length scale that governs the spatial extent of the nutrient surge. Note that as a no-slip boundary condition is imposed at the base of the mixed layer, the nutrient surge is imposed one grid-point above the base of the mixed layer, denoted by $z_{\mathrm{ml}+}$. For most of these simulations, the values $Q=130$ and $\sigma_{X Y}=7.6$ were chosen. This creates a highly localised source, some 100 times the background. The source is localised because a value of $\sigma_{x y}=7.6$ ensures that outside a circle of radius $25 \mathrm{~m}$ or so from the centre, the nutrient flux value falls back to within a few per- 
cent of its background level. Here the spatial extent of the nutrient source is on the length scale associated with that of a high-frequency internal wave (Boegman et al. 2003). However, as will be demonstrated later, the spatial extent of this nutrient flux does not have a qualitative effect on the solutions. Even if a uniform nutrient flux is prescribed, only relatively minor changes to the levels of patchiness in the phytoplankton distribution are brought about (see the subsequent discussion surrounding Fig. 9). Since the uptake term switches off whenever $N>2$, there is a cap as to how much extra $P$ growth such a source will stimulate. With the strength of the source imposed, $N>2$ is reached within $2 \mathrm{~d}$ at all points in the domain, which means that the phytoplankton perceive the nutrient field as homogeneous after this time. The nutrient field itself has no cap imposed, but any nutrient concentration with a value of $N>2$ has no additional effect to phytoplankton growth.

Initial conditions of $P_{0}=Z_{0}=0.5$ and $N_{0}=1$ were chosen so that biological oscillations would be initiated in and around the co-existence equilibrium point $(\hat{N}, \hat{P}, \hat{Z})=(0.43,0.85,1.56)$ (see Lewis et al. 2017 for details). An important point concerning the limit cycles of the predator-prey dynamics is that while they may not mimic reality, they do produce periodic phytoplankton blooms. The work carried out is concerned with the spatial heterogeneity brought on during a phytoplankton bloom and while the timescale and periodicity of the bloom may not be realistic, the spatial patchiness produced should depend much more on the flow-field dynamics. A time frame that is feasible for the LES to simulate is roughly 3-4 wk due to the computationally expensive nature of LES. A limit cycle timescale was chosen to be $\sim 10 \mathrm{~d}$ to capture at least 2 phytoplankton blooms, the initial bloom being highly likely to depend (spatially) on the homogeneous initial conditions prescribed.

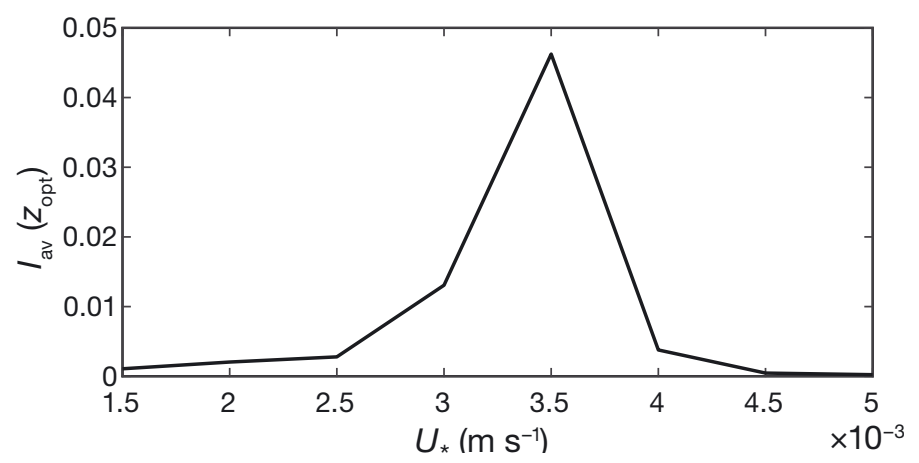

Fig. 1. Optimum patchiness intensity $I_{\text {av }}\left(U *, Z_{\text {opt }}\right)$ for a range of wind-stress $(U \cdot)$ values

\section{RESULTS}

To try and establish how planktonic patchiness is influenced by the physical forcings driving the boundary layer, one needs to assess both the lateral patchiness and the depth-dependent patchiness. One can do this by introducing the (lateral) patchiness intensity measure:

$$
I(U \cdot, z, t)=\frac{\left\langle P^{\prime 2}\right\rangle}{\langle P\rangle^{2}}
$$

Here \langle\rangle denotes a horizontal average, such that $\langle P\rangle+P^{\prime}=P$. This measure is similar to other metrics used in many previous studies to measure biological patchiness (Fessler et al. 1994, Reigada et al. 2003, Lewis 2005, Durham et al. 2011). Notice that when $\langle P\rangle$ is close to zero, $I$ is very large by definition, but this is of little interest. To mitigate this, a filter is applied to $I$ when $\langle P\rangle$ falls below a threshold of $0.1-$ a value deemed small. The filtered measure is defined as:

$$
I(U *, Z, t)=0 \quad\langle P\rangle<0.1
$$

One can average $I$ over a simulation time, $T$, i.e.:

$$
I_{\mathrm{av}}(U *, z)=\frac{1}{T} \int_{0}^{T} I \mathrm{~d} t
$$

and then locate the depth at which $I_{\mathrm{av}}(U *, Z)$ is maximised, i.e. $\max _{z}\left[I_{\mathrm{av}}\left(U_{*}, z\right)\right]=I_{\mathrm{av}}\left(U_{*}, z_{\text {opt }}\right)$, where $z_{\text {opt }}$ is the optimum depth. A series of simulations were run for different values of $U$. and $I_{\mathrm{av}}\left(U_{*}, Z_{\mathrm{opt}}\right)$ was computed across each boundary layer. The results are shown in Fig. 1. One can see from Fig. 1 that there is a peak in patchiness intensity at an intermediate wind stress of $U *=3.5 \times 10^{-3} \mathrm{~m} \mathrm{~s}^{-1}$ and then the signal decreases as the wind stress increases. From these results, it is clear that values of $U .>4 \times 10^{-3} \mathrm{~m}$ $\mathrm{s}^{-1}$ do not permit significant patch formations as the turbulent mixing spans the mixed layer completely. $U_{*}=4 \times 10^{-3} \mathrm{~m} \mathrm{~s}^{-1}=U_{\text {crit }}$ will be deemed critical for the generation of significant patchiness. There is also only a small signal for low wind-stress values, which suggests that there are insufficient levels of mixing to promote patchiness. As $U * \rightarrow 0$, the flow field will tend towards stagnation. In this regime, the only form of transport will be molecular diffusivity (eddy diffusivity will be zero due to zero shear in the flow field). In this regime, nutrient concentrations will disperse and spread out in all directions, meaning relatively high concentrations of nutrients will not be sustained in laterally localised regions of the water column. Hence, $I_{\mathrm{av}}$ will tend towards a small value over time. This finding is initially counterintuitive, as 
one might expect patchiness to decrease monotonically as the wind speed (and hence turbulent mixing) is increased. However, for lower wind speeds, vertical currents are not as prevalent and hence nutrients near the bottom of the mixed layer cannot be advected up the water column effectively to facilitate strong patchiness.

To understand the behaviour of $I_{\mathrm{av}}\left(z_{\mathrm{opt}}\right)$ a little better, it is necessary to investigate how $\langle P(z, t)\rangle$ varies with depth. Fig. 2 shows that for low (Fig. 2a) and intermediate (Fig. 2b) levels of wind forcing, biological oscillations are out of phase and exhibit different amplitudes. This demonstrates that the phytoplankton communities are not well mixed across the mixed layer and behave according to their local (biological) depth-dependant parameters. This is likely to be an indicator for the formation of biological patchiness, as it reveals that high levels of turbulent mixing are not present to homogenise the scalar fields over the mixed layer. For high levels of wind forcing (Fig. 2c), however, the biological dynamics become independent of depth. Concentration fields at all depths merge into a single oscillation, indicating that microorganisms are being vigorously mixed throughout the boundary layer. This type of behaviour is termed 'phase locking'. Although it cannot be seen in Fig. 2a,b, a certain proportion of curves near to the surface fall on top of each other, indicating there is a subset depth interval near the surface that is also phase-locked. One sees a wider spread of concentrations for the low windstress, compared with the medium wind-stress case. This can be explained for the low wind-stress case by there being a larger non-'phase-locked' depth range at which the biological model is prominent over the physical model. This larger spread of concentrations leads one to believe that horizontal heterogeneity must also be larger, but this is not necessarily the case. One can consider a zero wind-stress case where the flow is static. In this case, every depth would be out of phase owing to parameters such as depth-dependant light levels. In this case, the concentrations would experience a maximum spread of different population dynamics, but there would be no lateral dependant terms to induce horizontal patchiness. This means that for horizontal patchiness to form, there must be a certain amount of mixing to generate nutrient transport laterally at a particular depth, but at the same time, the mixing cannot be so strong as to drive the system into phase-locked mode.

To demonstrate this vertical homogenisation (phaselocking), one can use another measure analogous to that of the patchiness intensity in Eq. (13). This is defined by: where:

$$
I_{z}(U \cdot)=\frac{1}{M K} \sum_{j=1}^{K} \sum_{i=1}^{M} \frac{\left(\left\langle P\left(z_{i}, t_{j}\right)\right\rangle-\stackrel{\vee}{P}\left(t_{j}\right)\right)^{2}}{\stackrel{\vee}{P}\left(t_{j}\right)^{2}}
$$

$$
\stackrel{\vee}{P}\left(t_{j}\right)=\frac{1}{M} \sum_{i=1}^{M}\left\langle P\left(z_{i}, t_{j}\right)\right\rangle
$$

$I_{z}$ is a metric describing the level of heterogeneity across the mixed layer, $K$ is the reciprocal of the sampling frequency and $M$ is the number of vertical grid points. So, for example, when $I_{z}=0$, then the biology is in a completely phase-locked mode. Fig. 3 shows that for wind-stress values of $U \cdot \geq U_{\text {crit, }}$ the biology is effectively phase locked, as $I_{z}$ is very small. This supports the hypothesis that phase locking is strongly correlated with horizontal homogenisation. Here, the statistics that have been used to diagnose biological patchiness only give a general idea of the amount of mixing throughout the entire boundary layer. They do not provide any insight into the depth dependence of the turbulent mixing. This can be examined by using the phytoplankton as a proxy, to show how the wind and wave forcing influence the boundary layer mixing depth, i.e. how penetrative it is. Although phytoplankton are subject to both growth and decay, they are still passive with respect to the flow and can act in the role of a tracer. Fig. 4 shows that for low wind stress (Fig. 4a), $\langle P\rangle$ concentrations do not change with depth within the top $10 \mathrm{~m}$ or so of the boundary layer, demonstrating that the turbulence is strong enough to mix this portion of the boundary layer, but no more. Concentrations below this point are much more variable, indicating that the dynamics are primarily governed by the depthdependent biological parameters (e.g. light levels, nutrients). At an intermediate wind-stress value $U \cdot=3.5 \times 10^{-3} \mathrm{~m} \mathrm{~s}^{-1}$ (Fig. $4 \mathrm{~b}$ ), there is enough turbulence to mix down to approximately $25 \mathrm{~m}$ of the boundary layer, as $\langle P\rangle$ remains uniform up until this point. This example is important, as it indicates that mixing is taking place close to the bottom of the mixed layer where nutrient replenishment is imposed. Finally, for high wind-stress values $U * \geq U_{\text {crit }}$ (Fig. 4c), the biology is completely mixed, as there is no depth dependence in concentration and the biological dynamics are not strong enough to overcome the physical forcing mechanism. Note that in all graphs shown in Fig. 4, the depth at which homogeneity ceases is independent of time.

One can use the behaviour of $\langle P\rangle$ profiles to ascertain a mixing depth, $Z_{\text {mix }}$ for all simulated $U$. values. Let:

$$
Z_{\text {mix }}=\min _{z}\left[\operatorname{var}_{t}\left(P_{z}\right)>1 \times 10^{-3}\right]
$$

where $P_{z}=\partial\langle P\rangle / \mathrm{d} z$ and $\operatorname{var}_{t}$ represents a variance taken across all time outputs. In this expression, an 


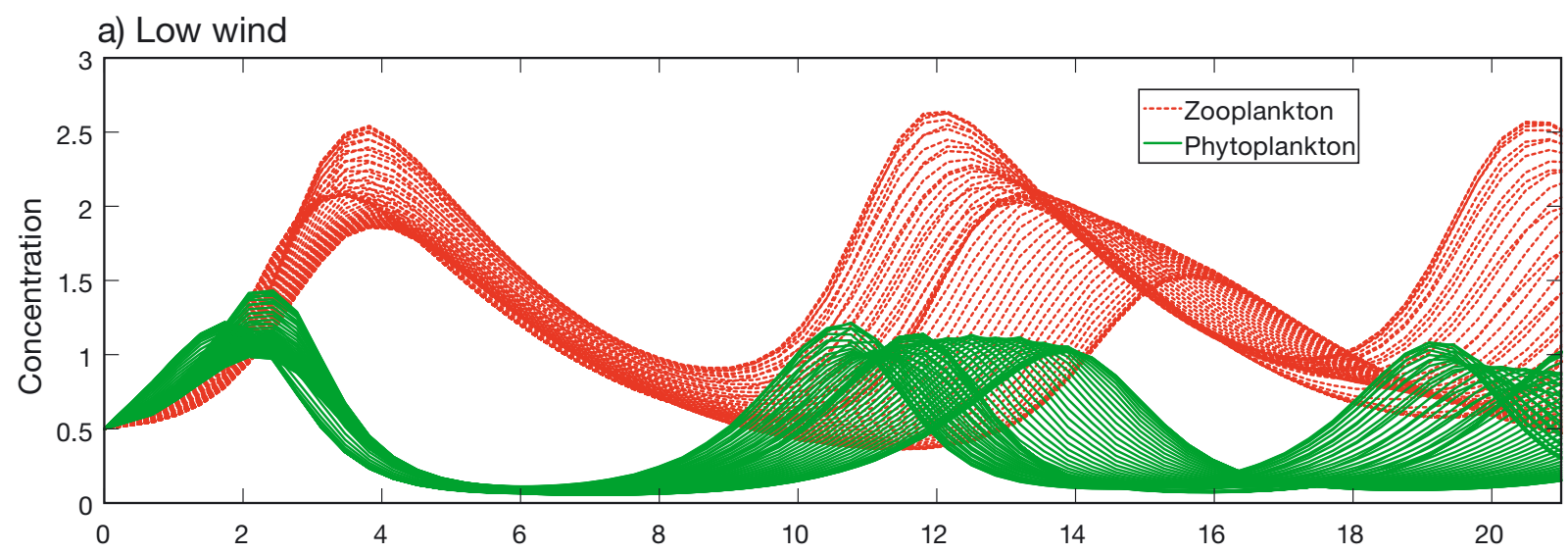

b) Intermediate wind

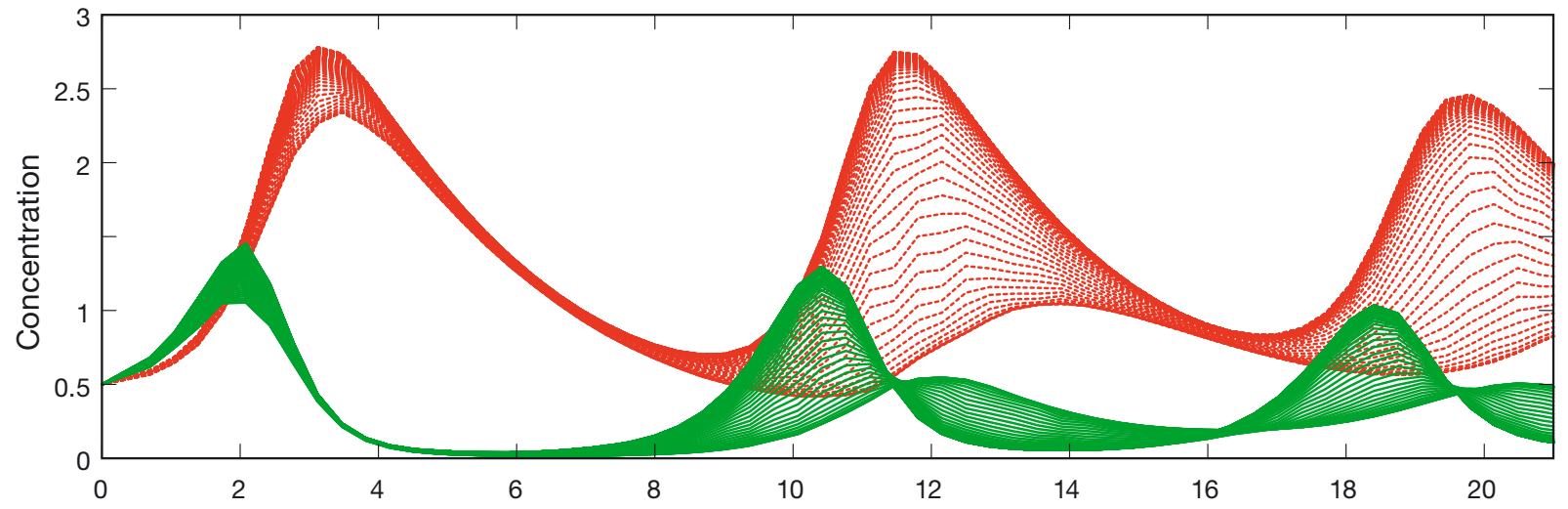

c) High wind

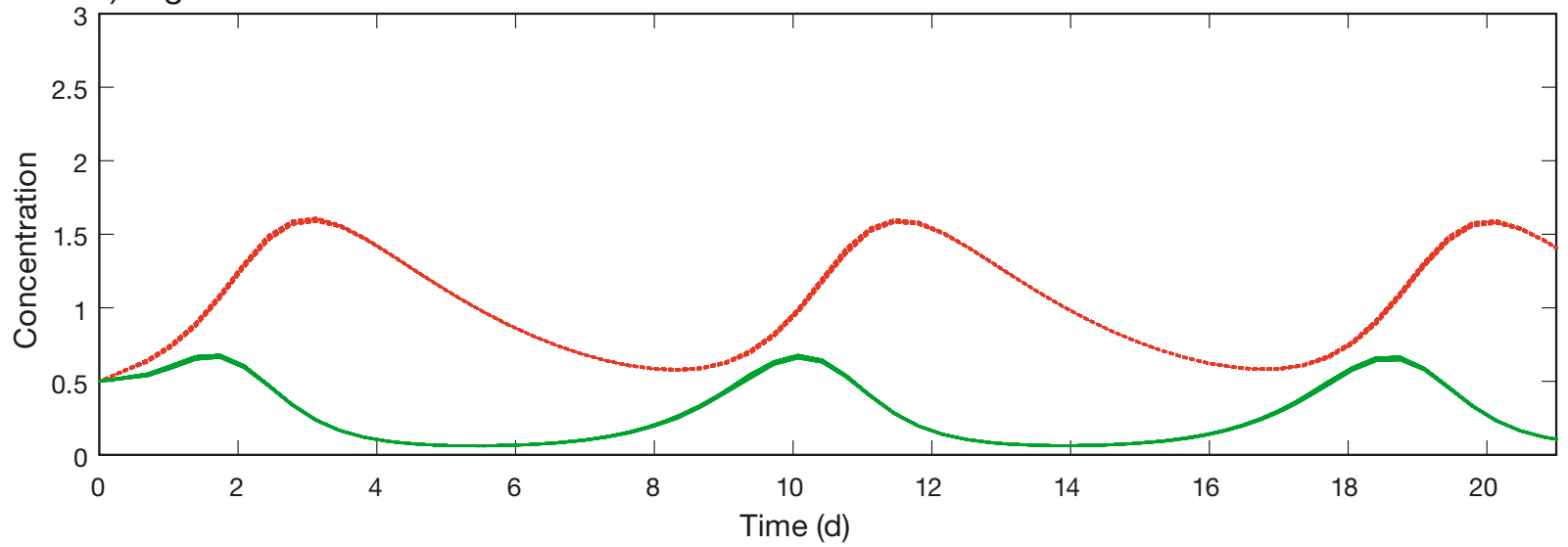

Fig. 2. Dynamics of phytoplankton and zooplankton concentrations calculated from the model. The solid (green) lines show phytoplankton concentration at each depth level and the dotted (red) lines show the zooplankton concentrations also across all depth levels. A comparison was made between (a) low wind stress $\left(U .=2 \times 10^{-3} \mathrm{~m} \mathrm{~s}^{-1}\right)$, (b) intermediate wind stress $(U \cdot=$ $\left.3.5 \times 10^{-3} \mathrm{~m} \mathrm{~s}^{-1}\right)$ and (c) high wind stress $\left(U .=5 \times 10^{-3} \mathrm{~m} \mathrm{~s}^{-1}\right)$, illustrating the phase-locking effect (across depth) at high wind forcing

arbitrary threshold value of $1 \times 10^{-3}$ is given and the shallowest depth (given by the $\min _{z}$ operator) at which the logical expression is true is termed the mixing depth, $z_{\text {mix }}$. In other words, $z_{\text {mix }}$ is the depth at which $\langle P\rangle$ profiles cease to be uniform (and hence mixed) with depth. Fig. 5a shows a plot of $z_{\text {mix }}$ against $U$. The monotonic deepening of the mixing layer is observed and one can surmise that a laminar band of water lies between this curve and $z_{\mathrm{ml}}$. One expects to find appreciable patchiness between $z_{\text {mix }}$ and $z_{\mathrm{ml}}$ and homogenised plankton concentrations above $z_{\text {mix }}$. Note that once $z_{\text {mix }}=z_{\mathrm{ml}}$ at $U . \geq U_{\text {crit }}$, no patch formations are likely. This metric also correlates well with levels of vertical velocity variance, a measure of the 


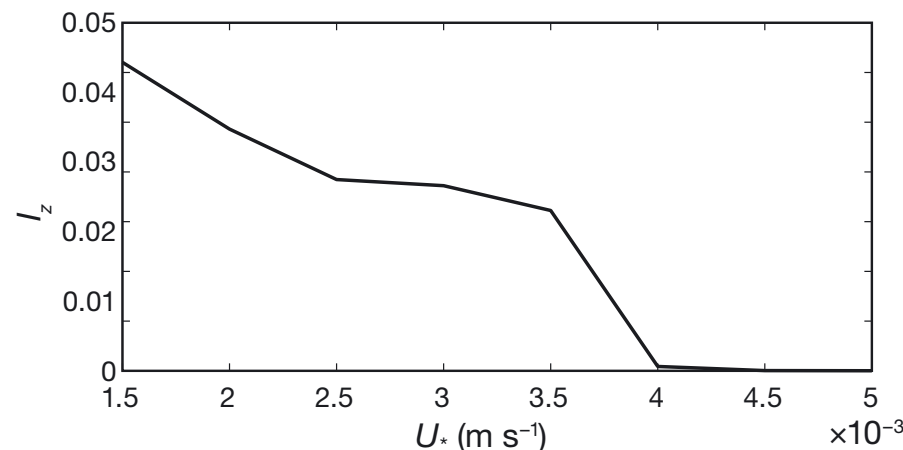

Fig. 3. Relationship between the level of wind stress (U.) subjected to the boundary layer and the level of (scaled) variance between phytoplankton concentrations at each depth $\left(I_{z}\right)$, averaged over time. The lower the variance, the more 'phase locked' the system is in terms of depth-dependent heterogeneity

strength of the vertical mixing and hence the strength of the Langmuir cells (Fig. 5b), where boundary layer thickness clearly increases monotonically with wind stress until the behaviour levels off at $U . \geq U_{\text {crit }}$ when the mixing depth reaches the mixed-layer depth. To illustrate further how the phytoplankton concentrations react to wind forcing, one can assess the levels of lateral heterogeneity to determine the depths at which patch formations are most likely to form. For this purpose, it is easiest to use the metric $I_{\mathrm{av}}(U \cdot, z)$ defined in Eq. (13). Fig. 6a,c shows that lateral patch- iness is unlikely to occur at either low or high levels of wind forcing. However, if the wind stress is set to an intermediate level, as shown in Fig. 6b, a much stronger signal emerges. One sees that patches accumulate around $25 \mathrm{~m}$, within the laminar band, where turbulent mixing ceases to dominate the system (see Fig. 4b). Fig. 7 shows a snapshot, taken at $z_{\text {opt }}$ at a point in time when the patchiness intensity is high at an intermediate friction velocity of $U .=3.5 \times$ $10^{-3} \mathrm{~m} \mathrm{~s}^{-1}$. What is most striking is the structure of the horizontal patches, in that they are closely correlated to the structure of the Langmuir cells. Langmuir cells manifest themselves as a series of upwellings and downwellings (Fig. 7d) (see McWilliams et al. 1997 and Lewis 2005 for details). Note the angular deflection of the Langmuir cells from the wind direction, which is due to inertial oscillations instigated by the rotation term in the momentum equations (Lewis \& Belcher 2004). Fig. 8 shows a vertical cross-section, again at a point in time when patchiness intensity is high. Upwelling zones and downwelling zones can be seen in the NPZ distributions and clearly demonstrates the mechanism of Langmuir cells inducing horizontal patchiness. This also indicates that the structure of the phytoplankton community is dependent on the flow field and not on the geometric extent of the imposed nutrient flux boundary condition. To verify this assertion, 2 control runs were completed, a) Low wind

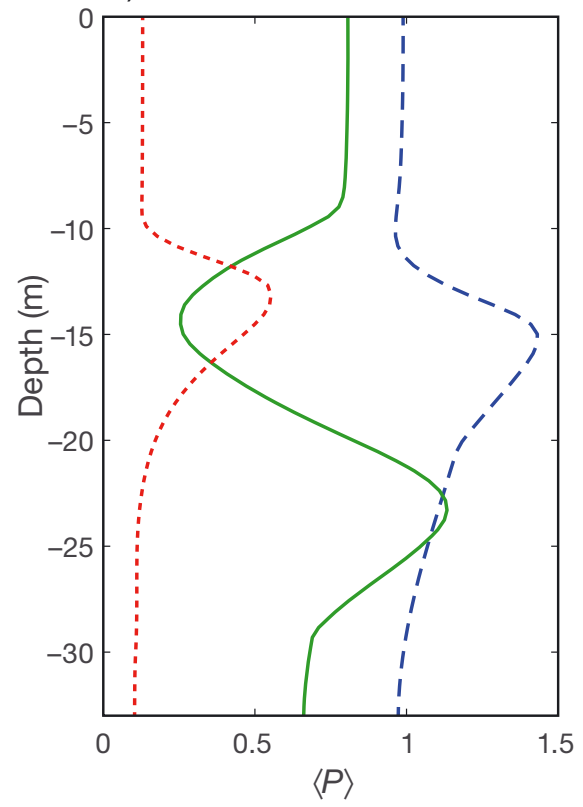

b) Intermediate wind

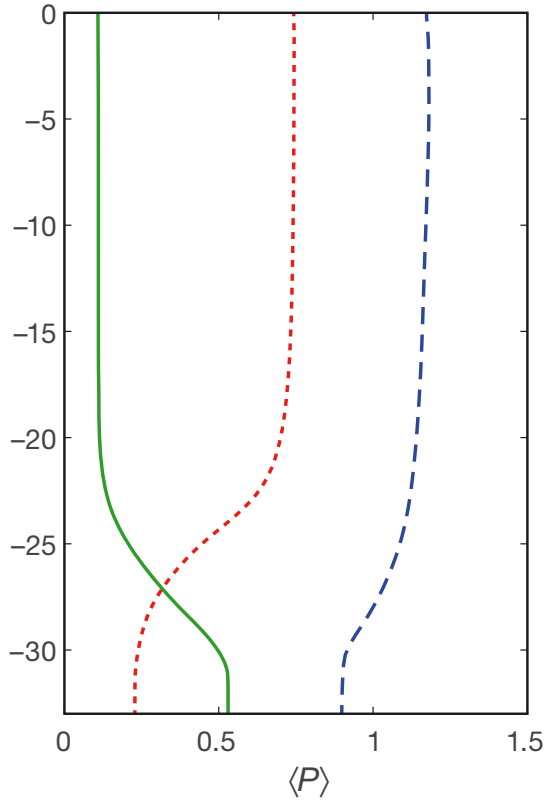

c) High wind

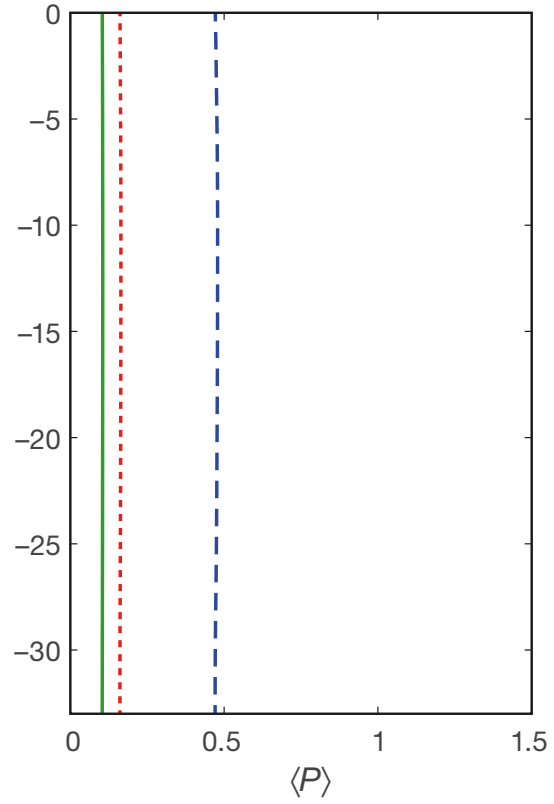

Fig. 4. Depth profiles of the horizontal average phytoplankton concentration $\langle P\rangle$ at instantaneous points in time. The dashed (blue) line shows the profile after $3 \mathrm{~d}$, the solid (green) line shows the profile at $10 \mathrm{~d}$ and the dotted (red) line shows the profile at $17 \mathrm{~d}$. A comparison was made between (a) low wind stress $\left(U_{*}=2 \times 10^{-3} \mathrm{~m} \mathrm{~s}^{-1}\right)$, (b) intermediate wind stress $\left(U *=3.5 \times 10^{-3} \mathrm{~m} \mathrm{~s}^{-1}\right)$ and (c) high wind stress ( $\left.U_{*}=5 \times 10^{-3} \mathrm{~m} \mathrm{~s}^{-1}\right)$ 

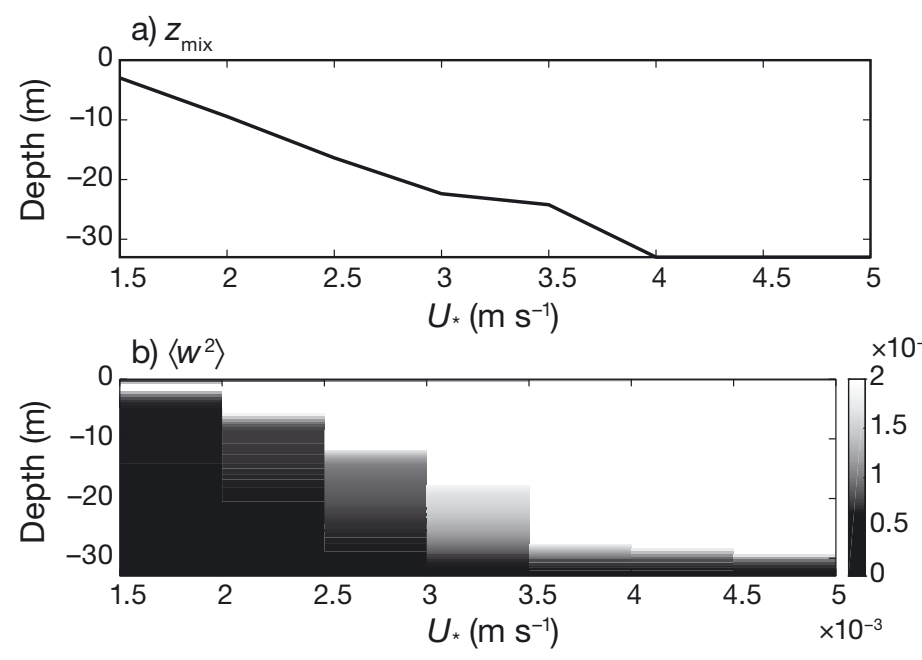

Fig. 5. (a) Mixing depth $z_{\text {mix }}$ and (b) vertical velocity variance $\left\langle w^{2}\right\rangle$ varying as a function of wind stress. Lighter shades in (b) indicate high levels of vertical mixing. Note here that for $U . \geq 4 \times 10^{-3} \mathrm{~m} \mathrm{~s}^{-1}=u_{\text {crit }}$, both variables indicate that high mixing extends throughout the mixed layer

both using the same physical and biological parameters and the same average nutrient flux into the boundary layer, with varying distributions of the nutrient flux. It is unlikely for any patchiness to be observed in the high-wind-forcing case. In the lowwind cases, the laminar band between the bottom boundary and the mixing layer will be large and so the nutrient dynamics will be more diffusive, effec- tively smoothing out the influence of the geometry of the bottom nutrient boundary condition. Therefore, the decisive scenario occurs when the wind forcing is intermediate. Hence, the tests were conducted with $U \cdot=3.5 \times 10^{-3} \mathrm{~m} \mathrm{~s}^{-1}$. One simulation was prescribed with a Gaussian nutrient pump as described in 'Boundary conditions for the LES-NPZ model' and the other prescribed with a laterally uniform nutrient flux. Fig. 9 shows the resulting $I_{\text {av }}$ for both cases. The crucial point is that, although the uniform flux results in a somewhat lower average patchiness intensity, the depth at which it is maximum is consistent. The quantitative differences seen are caused by nutrients being advected towards their closest upwelling region in the Gaussian pump case. This results in relatively rapid phytoplankton growth over a relatively small region, leading to high-intensity signatures. By contrast, in the uniform case, the nutrients have no preference for the particular upwelling region, so the resulting growth is less intense and less localised. Nevertheless, it is still sufficient to produce a significant intensity signature within the laminar band. These results indicate that patch formations remain robust, irrespective of the geometric set-up of the nutrient boundary condition. There is no correlation between the latter and the structure of the patch formations. Instead, patchiness occurs where nutrients are transported (not where it originates), and the nature of the transport is regulated by the Langmuir a) Low wind

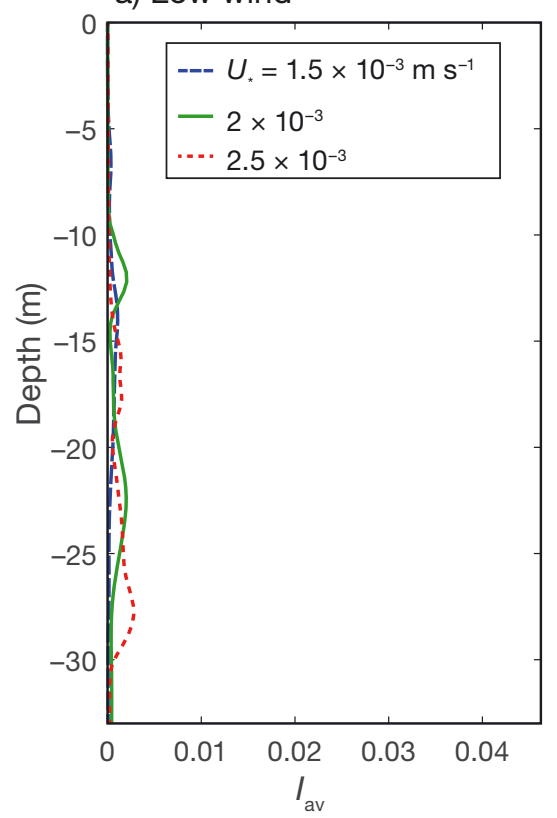

b) Intermediate wind

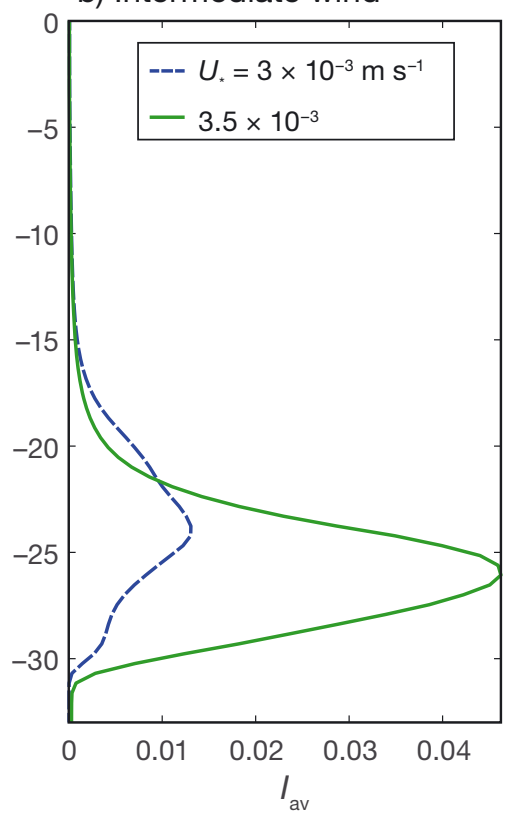

c) High wind

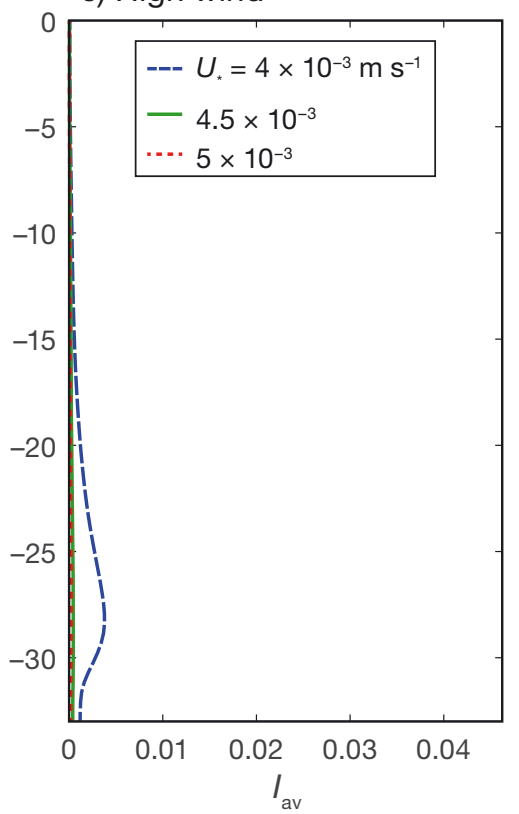

Fig. 6. Quantification of average lateral patchiness intensity $\left(I_{\text {av }}\right)$, for (a) low, (b) intermediate and (c) high wind-stress (U.) regimes. This illustrates the optimum condition for phytoplankton patchiness 

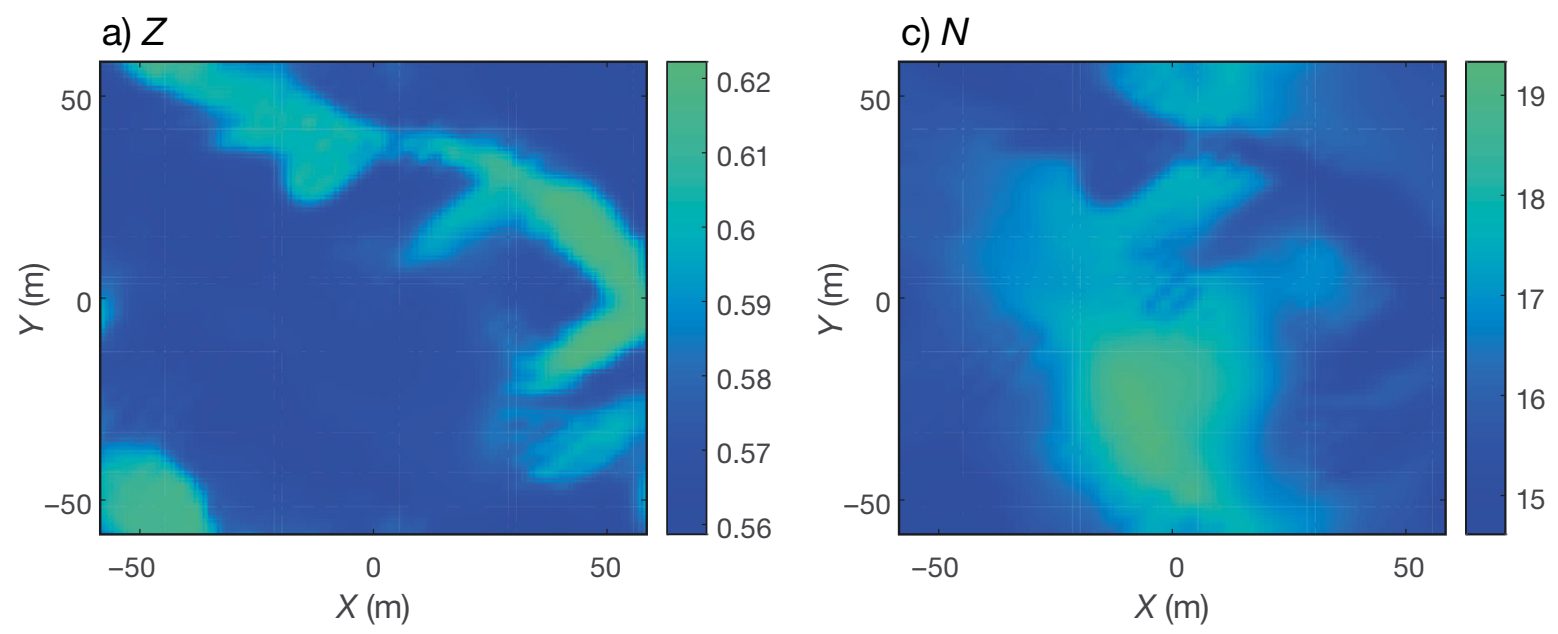

b) $P$

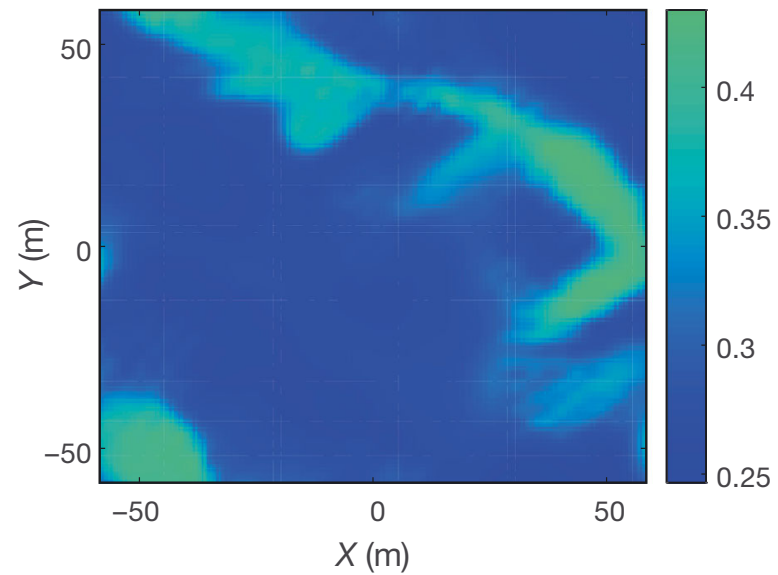

d) $w$

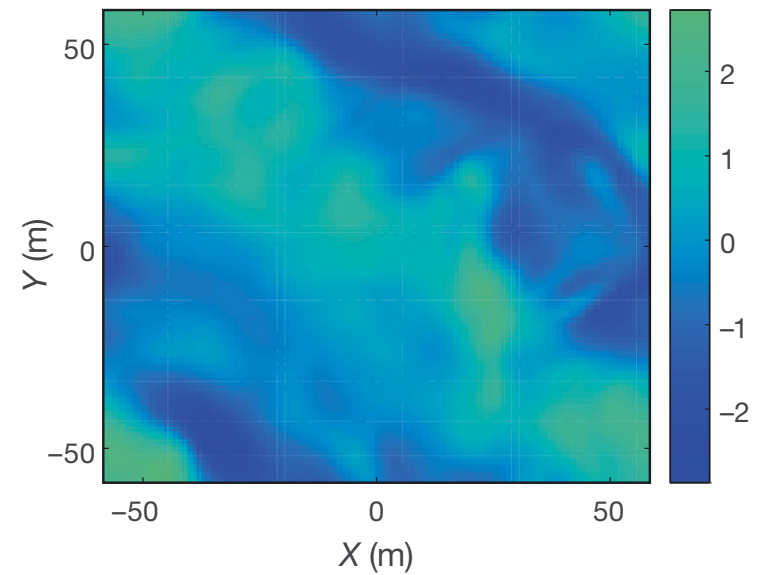

Fig. 7. Snapshot of (a) zooplankton, (b) phytoplankton, (c) nutrient and (d) vertical velocity (w) at $z_{\mathrm{opt}}$ for an intermediate windstress value of $U \cdot=3.5 \times 10^{-3} \mathrm{~m} \mathrm{~s}^{-1}$

a) $N$

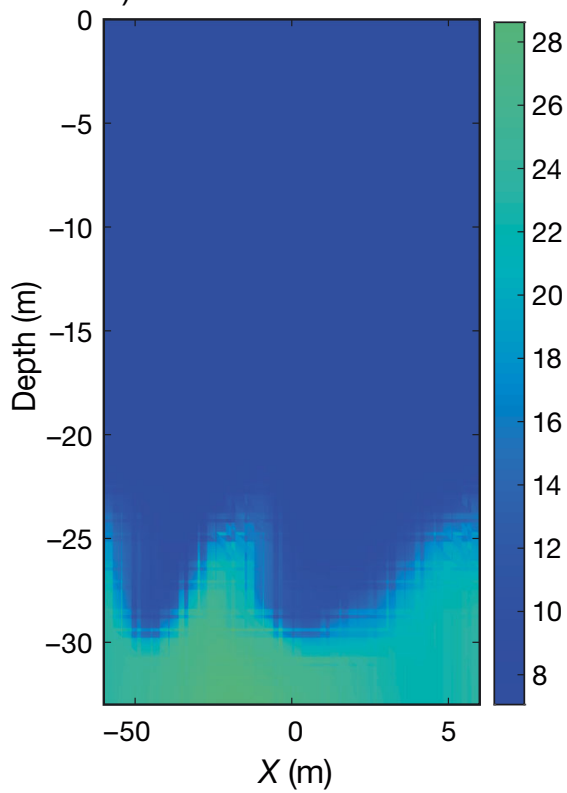

b) $P$

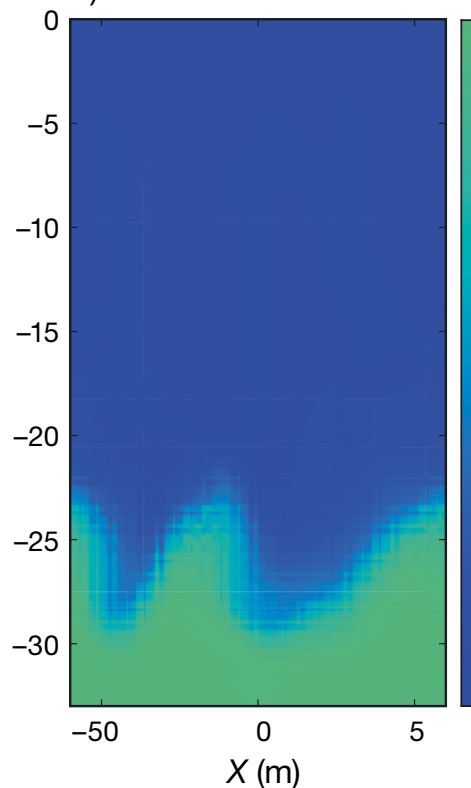

c) $Z$

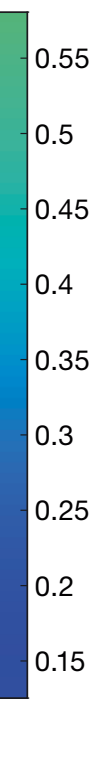

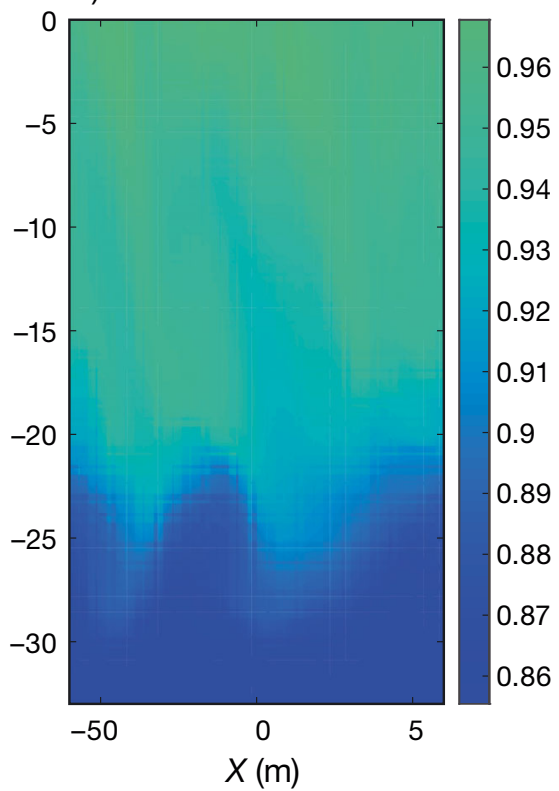

Fig. 8. (a) Nutrient, (b) phytoplankton and (c) zooplankton concentrations after 12 d of simulation time, when the phytoplankton community is starting the bloom phase of the limit cycle. Here, $U .=3.5 \times 10^{-3} \mathrm{~m} \mathrm{~s}^{-1}$ 


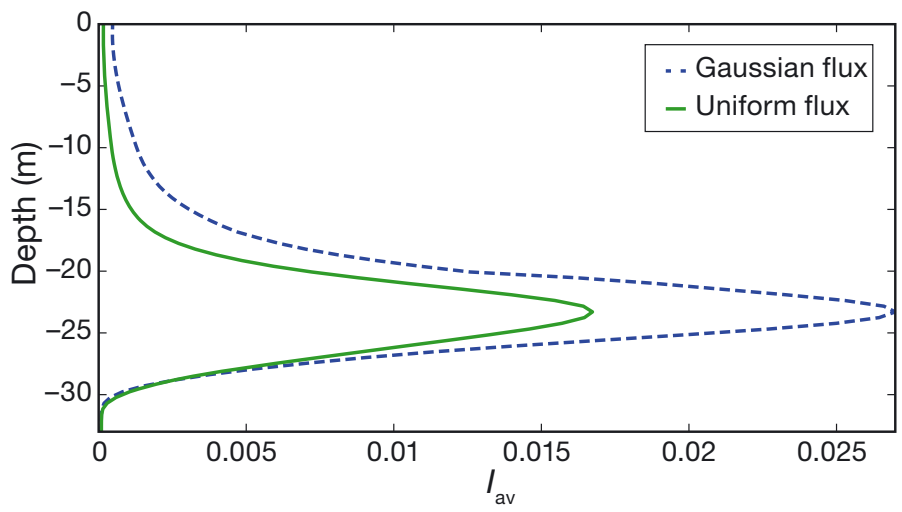

Fig. 9. Time-averaged patchiness intensity $I_{\text {av }}$ against depth for $U .=3.5 \times 10^{-3} \mathrm{~m} \mathrm{~s}^{-1}$. The blue dotted line indicates a simulation prescribed by the Gaussian nutrient pump used in this work, and the green solid line indicates a simulation prescribed by a uniform nutrient pump

cell structure induced by the wind forcing. Furthermore, it shows that Langmuir circulations are taking control of the distribution of the biological fields, separating them into 2 distinct populations of upwelling and downwelling inhabitants.

This correlation of planktonic patchiness with Langmuir circulations is reinforced by the result of 2 similar boundary layer simulations. One boundary layer was driven purely by wind forcing and no surface-wave effects (Fig. 10a) and one Langmuir circulation run driven by both wind and surface-wave forcing terms
(Fig. 10b). Each figure shows the correlation $\left\langle w^{\prime} P^{\prime}\right\rangle$ of the vertical velocity and the phytoplankton field. Fig. 10b shows a strong correlation signal around the mixing depth $z=25 \mathrm{~m}$ in the Langmuir simulation, which is completely absent in the purely wind-driven case. These experiments show clearly that Langmuir circulations are directly responsible for the strong depth-dependent patchiness presented in this work. This is a surprising result, as the presence of Langmuir circulations would imply a much more energetic boundary layer compared with the wind-driven case, which would intuitively imply destruction of heterogeneity. But instead, they can, under the right conditions, produce enhanced biological structure.

\section{DISCUSSION}

Phytoplankton patchiness is an ubiquitous feature of near-surface ocean boundary layers. The work carried out in this study attempts to establish under what conditions patchiness is likely to occur. In simple terms, this study demonstrates that a compromising amount of surface forcing (through wind and waves) is required to induce patchiness signatures. If forcing is too weak, the flow field is quiescent and upwellings are not set up to pull nutrients up into laterally heterogeneous zones. If forcing is too strong, the whole boundary layer becomes turbulent and
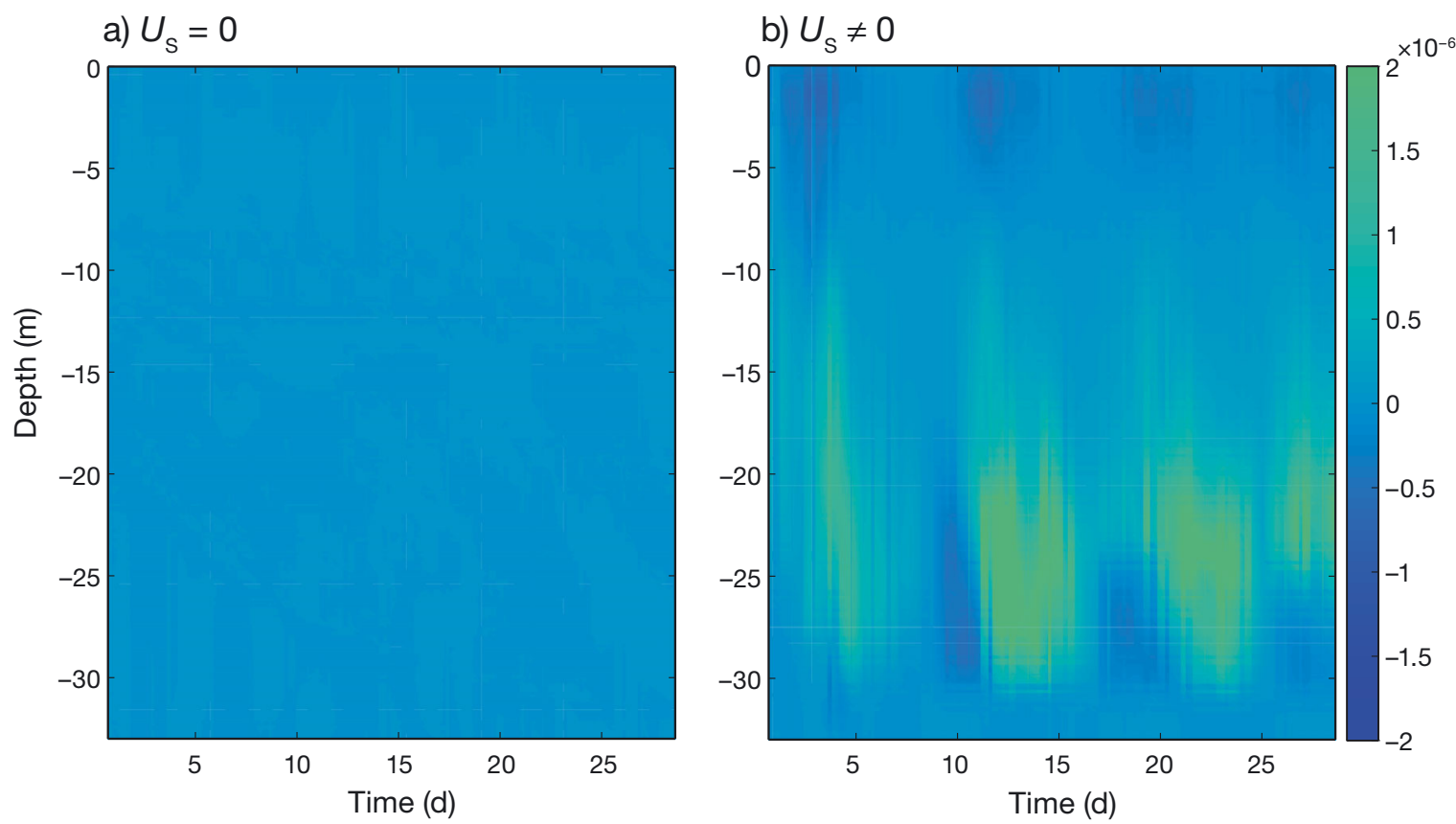

Fig. 10. The correlation between vertical currents and phytoplankton concentration $\left\langle W^{\prime} P^{\prime}\right\rangle$ for $U *=3.5 \times 10^{-3} \mathrm{~m} \mathrm{~s}^{-1}$. (a) Langmuir circulation switched off $\left(U_{\mathrm{S}}\right)$ and $(\mathrm{b})$ Langmuir circulation switched on 
concentrations become vigorously mixed and homogenised throughout. The optimum condition for biological patchiness occurs when surface forcing is at an intermediate level, not too strong, nor too weak. When this level is achieved, the upper portion of the boundary layer becomes vigorously mixed and the lower portion becomes quasi-quiescent with established upwellings (and downwellings). This means that in the laminar band between $z_{\text {mix }}$ and $z_{\text {ml, }}$ nutrients are advected upwards into laterally heterogeneous zones whilst the lateral mixing is insufficient to disperse the resultant patchiness. Langmuir circulations are of key importance to this process, as they penetrate quite deeply into the mixed layer, creating zones of high vertical mixing combined with relatively low lateral transport. So any biological patches that accrue through growth tend to remain relatively heterogeneous. It was also found that the mechanism by which nutrients are injected into the mixed layer does not have a profound effect on the patchiness in terms of the depth at which patchiness is formed. However, if the spatial extent of the nutrient source is small enough, advection into the closest upwelling zones is likely, skewing the patchiness distribution and increasing the patch signature. This is an important result, as nutrient surges come in a wide range of spatio-temporal scales. Finally, it should be noted that the frequency of the limit cycles in the plankton population dynamics is overly idealised, due to the simplicity of the biological model. To test the dependence of the limit-cycle behaviour on horizontal patchiness, one should make use of a more realistic biological model.

Future work will be carried out to ascertain whether there is a natural scaling between the depth and strength of phytoplankton patchiness, the depth at which nutrients are injected into a system and the mixing depth associated with different levels of wind and wave forcing. Furthermore, with new insights into how phytoplankton populations may separate out into upwelling and downwelling zones when Langmuir circulations are present, work will be undertaken to investigate plankton bloom duration when subjected to different levels of wind and wave forcing.

Acknowledgements. The authors thank Dr Jeff Polton and Dr Rachel Bearon for their time spent proof reading the manuscript: their insights proved invaluable to the work and the authors are beyond grateful for that. The authors also thank the anonymous reviewers, whose comments made a large positive impact on the manuscript as a whole. This work was funded by the Natural Environment Research Council (grant reference number NE/D01073X/1).

\section{LITERATURE CITED}

Allen JI, Howland RMH, Bloomer N, Uncles RJ (1999) Simulating the spring phytoplankton bloom in the Humber plume, UK. Mar Pollut Bull 37:295-305

* Baird ME, Emsley SM (1999) Towards a mechanistic model of plankton population dynamics. J Plankton Res 21: 85-126

* Beman JM, Arrigo KR, Matson PA (2005) Agricultural runoff fuels large phytoplankton blooms in vulnerable areas of the ocean. Nature 434:211-214

* Boegman L, Imberger J, Ivey GN, Antenucci JP (2003) Highfrequency internal waves in large stratified lakes. Limnol Oceanogr 48:895-919

Craik ADD, Leibovich S (1976) A rational model for Langmuir circulations. J Fluid Mech 73:401-426

* Dore JE, Letelier RM, Church MJ, Lukas R, Karl DM (2008) Summer phytoplankton blooms in the oligotrophic North Pacific subtropical gyre: historical perspective and recent observations. Prog Oceanogr 76:2-38

Durham WM, Stocker R (2012) Thin phytoplankton layers: characteristics, mechanisms, and consequences. Annu Rev Mar Sci 4:177-207

* Durham WM, Climent E, Stocker R (2011) Gyrotaxis in a steady vortical flow. Phys Rev Lett 106:238102

* Durham WM, Climent E, Barry M, De Lillo F, Boffetta G, Cencini M, Stocker R (2013) Turbulence drives microscale patches of motile phytoplankton. Nat Commun 4:2148

Edwards AM, Brindley J (1996) Oscillatory behaviour in a three-component plankton population model. Dyn Stab Syst 11:347-370

Fasham MJR, Ducklow HW, McKelvie SM (1990) A nitrogen-based model of plankton dynamics in the oceanic mixed layer. J Mar Res 48:591-639

* Fessler JR, Kulick JD, Eaton JK (1994) Preferential concentration of heavy particles in a turbulent channel flow. Phys Fluids 6:3742-3749

*Franks PJS, Wroblewski JS, Flierl GR (1986) Behavior of a simple plankton model with food-level acclimation by herbivores. Mar Biol 91:121-129

Gallager SM, Yamazaki H, Davis CS (2004) Contribution of fine-scale vertical structure and swimming behavior to formation of plankton layers on Georges Bank. Mar Ecol Prog Ser 267:27-43

*Gohin F, Lampert L, Guillaud JF, Herbland A, Nézan E (2003) Satellite and in situ observations of a late winter phytoplankton bloom, in the northern Bay of Biscay. Cont Shelf Res 23:1117-1141

Gran HH, Braarud T (1935) A quantitative study of the phytoplankton in the Bay of Fundy and the Gulf of Maine (including observations on hydrography, chemistry and turbidity). J Biol Board Can 1:279-467

*Harcourt RR, D'Asaro EA (2008) Large-eddy simulation of Langmuir turbulence in pure wind seas. J Phys Oceanogr 38:1542-1562

Hulburt EM (1968) Phytoplankton observations in the western Caribbean Sea. Bull Mar Sci 18:388-399

Koné V, Aumont O, Lévy M, Resplandy L (2009) Physical and biogeochemical controls of the phytoplankton seasonal cycle in the Indian Ocean: a modeling study. In: Indian Ocean biogeochemical processes and ecological variability. American Geophysical Union, Washington, DC, p 147-166

Leibovich S (1983) The form and dynamics of Langmuir circulations. Annu Rev Fluid Mech 15:391-427 
Lennert-Cody CE, Franks PJS (1999) Plankton patchiness in high-frequency internal waves. Mar Ecol Prog Ser 186: 59-66

Lewis DM (2005) A simple model of plankton population dynamics coupled with a LES of the surface mixed layer. J Theor Biol 234:565-591

Lewis DM, Belcher SE (2004) Time-dependent, coupled, Ekman boundary layer solutions incorporating stokes drift. Dyn Atmos Oceans 37:313-351

Lewis DM, Pedley TJ (2001) The influence of turbulence on plankton predation strategies. J Theor Biol 210:347-365

Lewis DM, Brereton A, Siddons JT (2017) A large eddy simulation study of the formation of deep chlorophyll/ biological maxima in un-stratified mixed layers: the roles of turbulent mixing and predation pressure. Limnol Oceanogr 62:2277-2307

Macías D, Rodríguez-Santana Á, Ramírez-Romero E, Bruno $M$ and others (2013) Turbulence as a driver for vertical plankton distribution in the subsurface upper ocean. Sci Mar 77:541-549

Mackas DL, Denman KL, Abbott MR (1985) Plankton patchiness: biology in the physical vernacular. Bull Mar Sci 37: 652-674

Martin AP (2003) Phytoplankton patchiness: the role of lateral stirring and mixing. Prog Oceanogr 57:125-174

Martin AP, Richards KJ, Bracco A, Provenzale A (2002) Patchy productivity in the open ocean. Global Biogeochem Cycles 16:1025

McWilliams JC, Sullivan PP, Moeng CH (1997) Langmuir turbulence in the ocean. J Fluid Mech 334:1-30

Mitchell JG, Yamazaki H, Seuront L, Wolk F, Li H (2008) Phytoplankton patch patterns: seascape anatomy in a turbulent ocean. J Mar Syst 69:247-253

Noh Y, Kang IS, Herold M, Raasch S (2006) Large eddy simulation of particle settling in the ocean mixed layer. Phys Fluids 18:085109

Oschlies A (2002) Can eddies make ocean deserts bloom? Glob Biogeochem Cycles 16:1106

Phillips OM (1977) The dynamics of the upper ocean. Cambridge University Press, New York, NY

Polton JA, Belcher SE (2007) Langmuir turbulence and

Editorial responsibility: Steven Lohrenz,

New Bedford, Massachusetts, USA deeply penetrating jets in an unstratified mixed layer. J Geophys Res Oceans 112:C09020

Reigada R, Hillary RM, Bees MA, Sancho JM, Sagués F (2003) Plankton blooms induced by turbulent flows. Proc R Soc B 270:875-880

* Rines JEB, McFarland MN, Donaghay PL, Sullivan JM (2010) Thin layers and species-specific characterization of the phytoplankton community in Monterey Bay, California, USA. Cont Shelf Res 30:66-80

* Ryan JP, Ueki I, Chao Y, Zhang H, Polito PS, Chavez FP (2006). Western Pacific modulation of large phytoplankton blooms in the central and eastern equatorial Pacific. J Geophys Res Biogeosci 111:G02013

Sandstrom H, Elliott JA (1984) Internal tide and solitons on the Scotian Shelf: a nutrient pump at work. J Geophys Res Oceans 89:6415-6426

* Sharples J, Tweddle JF, Mattias Green JA, Palmer MR and others (2007) Spring-neap modulation of internal tide mixing and vertical nitrate fluxes at a shelf edge in summer. Limnol Oceanogr 52:1735-1747

Siegel DA, Doney SC, Yoder JA (2002) The North Atlantic spring phytoplankton bloom and Sverdrup's critical depth hypothesis. Science 296:730-733

Smagorinsky J (1963) General circulation experiments with the primitive equations: I. the basic experiment. Mon Weather Rev 91:99-164

* Sullivan PP, Romero L, McWilliams JC, Melville WK (2012) Transient evolution of Langmuir turbulence in ocean boundary layers driven by hurricane winds and waves. J Phys Oceanogr 42:1959-1980

Taylor JR, Ferrari R (2011) Shutdown of turbulent convection as a new criterion for the onset of spring phytoplankton blooms. Limnol Oceanogr 56:2293-2307

Thorpe SA (2000) Langmuir circulation and the dispersion of oil spills in shallow seas. Spill Sci Technol Bull 6:213-223

*Williams RG, Follows MJ (1998) The Ekman transfer of nutrients and maintenance of new production over the North Atlantic. Deep Sea Res I 45:461-489

* Zhan C, Sardina G, Lushi E, Brandt L (2014) Accumulation of motile elongated micro-organisms in turbulence. J Fluid Mech 739:22-36

Submitted: November 21, 2016; Accepted: January 21, 2018 Proofs received from author(s): March 21, 2018 